\title{
Product liability and the virtues of asymmetric information
}

\author{
Florian Baumann • Tim Friehe
}

\begin{abstract}
This paper analyzes a two-period setup in which firms differ with respect to costs of care and may use care-taking to signal type to consumers, who are able to observe precaution taken only ex post. Applying the refinement of the intuitive criterion to the concept of the perfect Bayesian equilibrium, we establish a unique separating equilibrium for every share of harm borne by firms. For low levels of victim compensation, we show that (i) firms choose weakly higher care in a setting in which customers do not know the firms' type than in a setting in which they do, and (ii) the deviation in precaution taken due to asymmetric information on firm type is welfare-improving.
\end{abstract}

Keywords Tort law · Product liability - Signaling - Care level · Asymmetric information

\section{JEL Classification K13}

\section{Introduction}

Firms are liable for injuries suffered by consumers of defective products under product liability. In order to influence the frequency of product defects or the magnitude of consequences from product defects, firms invest in precautionary measures. The

\footnotetext{
F. Baumann (ه)

Department of Economics, Eberhard Karls University,

Melanchthonstr. 30, 72074 Tübingen, Germany

e-mail: tlorian.baumann@uni-tuebingen.de

T. Friehe

Department of Economics, University of Konstanz, Box D 136, 78457 Constance, Germany

e-mail: tim.friehe@uni-konstanz.de
} 
level of such investment is usually unobservable to consumers. However, consumers can gather information about product defects through their own use of the good after purchase, or through learning about other consumers' experiences with the products of a specific firm. Asymmetric information on care taken by the firm at the point in time at which the product is purchased by the consumer is a very realistic phenomenon. The presence of asymmetric information is often detrimental to efficiency (see, e.g., Rasmusen 2007). This tends to be true in the product liability context as well, if firms do not have to fully compensate victims (e.g., Shavell 2007).

Our study supposes that strict liability applies and shows that asymmetric information on firm type can induce higher precaution than in a setting in which consumers are aware of the firm's type. ${ }^{1}$ Asymmetric information on firm type is introduced in that consumers are uninformed about the firm's costs of taking care. Differences in care costs are due to, for example, firms using different technologies or production modes. Employing the equilibrium refinement of the 'intuitive criterion' established by Cho and Kreps (1987) to the concept of the perfect Bayesian equilibrium, we find a unique separating equilibrium for every share of harm for which the firm has to compensate. Most importantly, if the share of losses borne by the firm is sufficiently low, asymmetric information on firm type will certainly help to lower expected social costs.

These results are derived in the following simple framework. There is a firm which serves demand in two periods, where precaution costs are private information and may be either high or low. Consumers cannot observe precaution taken by the firm before the purchase of the good, but are concerned about the level of precaution taken by the firm because compensation in the event of an accident is not full. Incomplete compensation of victims of product-related accidents applies in many cases in reality (see, e.g., Endres and Lüdecke 1998). The expected precaution level taken by the firm therefore affects consumers' willingness to pay. In our setting, the level of precaution taken by the firm is perfectly revealed after purchases have taken place, i.e., we consider an experience good. This assumption is critical for our study but well established in the literature on product liability; see, e.g., Daughety and Reinganum (1995) and Marette et al. (2000). The informational setup applies in particular to newly launched products where, at first, little experience with the good exists, but information is accumulated over time (Daughety and Reinganum 1995, p. 1195). Two aspects support the relevance of this setting. First, it suffices that consumers learn about the accident probability instead of being required to know the precise level of care. Second, this information depends not only on a consumer's own observations, but may also be nourished by others' experiences of the good under consideration. For instance, according to Polinsky and Shavell (2009, p. 8), "consumers ... have many sources of . . information available to them. In 2007, for example, the top ten newspapers in the United States, with a total paid circulation of close to ten million people, published an estimated 2,900 articles related to product safety". Likewise, consumer reports may provide information on the safety attributes of a firm's products. Given the observed accident probability in the first period, consumers update their expectations about firm type. Since consumers know that firms choose precaution in the second

\footnotetext{
1 Product liability holds firms strictly liable for accidents due to defective products in most jurisdictions (e.g., Shavell 2004; Cooter and Ulen 2008; Geistfeld 2009).
} 
period according to their type, it may be of interest for high-cost firms to pool with low-cost firms, or for low-cost firms to separate from high-cost firms in the first period, as consumers' willingness to pay in period two will depend on expected care.

Our core results can be briefly explained as follows. Consumers are not informed about the investment in precaution when they buy the product, as we consider an experience good. This makes consumers' expectations irrelevant for the choice of actual care in a given period. Given that compensation is not full, firms do not take the full expected harm into account when choosing care. This leads to less than first-best care if consumers know the firm's type. If consumers do not know the firm's type, then strategic reasons may suggest choosing a different care level in period one. It may be that the high-cost firm chooses more care than it would in the setting in which consumers know about the firm's type, in order to pool with the low-cost firm. On the other hand, it may be that the low-cost firm chooses more care than in the setting in which consumers know about the firm's type, in order to discourage mimicking by the high-cost firm. For low levels of victim compensation, we establish that there does indeed exist an incentive for low-cost firms to signal firm type by increasing their level of care taken. This higher level of precaution by low-cost firms partly compensates the distortion due to the experience character of the good. Thus, asymmetric information on firm type can improve the outcome in a second-best sense, given that there is asymmetric information on precaution taken (Lipsey and Lancaster 1956).

There is a large body of literature on the economics of product liability (see Geistfeld 2009 for a recent survey). For instance, Daughety and Reinganum (2008) consider the voluntary disclosure of risk-related information via price signaling or costly disclosure, two aspects which we will not address. We also do not consider the possibility of contractually specified liability or warranties. In this domain, Wickelgren (2006) argues that consumers will waive liability in order to obtain a lower price because the precautionary decision has already been made by the firm at that point in time. Here, we consider mandatory product liability, which is a way of committing to not waiving liability. Product liability affects a firm's decision-making in several ways. For instance, it has been established that product liability may also impact on product differentiation (Endres and Lüdecke 1998). In our setup, precaution can be interpreted as an aspect of product quality, due to the fact that compensation in the event of an accident is not full. There are many papers which examine the relationship between prices and exogenous quality, such as Bagwell and Riordan (1991). In our study, we assume precaution to be endogenous. Daughety and Reinganum (1995) also consider endogenous safety in an asymmetric information setting, but regard signaling to occur via price. We cannot do justice here to this very rich literature, however, to the best of our knowledge, the topic we wish to analyze has not yet been the subject of scrutiny.

The structure of this paper is as follows. Section 2 describes the model, while the analysis is presented in Sect. 3. Section 4 concludes.

\section{The model}

The two-period model is kept simple in order to retain a focus on our main interests: the potential distortion in care-taking due to asymmetric information on firm type 
and the way in which the distortion in care affects welfare. First, we will describe demand for the good and then proceed with the description of the firm.

\section{Demand}

We assume that there is demand for one unit of the good. The consumers, who are risk-neutral, know that in the event of an accident, firms have to bear only the share $\gamma<1$ of harm under the strict liability regime, but cannot observe care actually taken by the firm until after the purchase. Harm in the case of an accident is denoted by $h$. We assume that consumers are willing to pay an amount of $v>h$ for one unit of the good but that they reduce this amount by the losses they expect to bear. The willingness to pay for the good is therefore dependent on expected care $\bar{x}_{t}$ in period $t, t=1,2$, where the expected accident probability is given by $\left(1-\bar{x}_{t}\right)$. As care-taking is unobservable ex ante, the care level that consumers expect from the firm is not affected by actual care-taking in the given period. However, in equilibrium the conjectured care level will prove correct given the beliefs about firm type, i.e., we assume rational expectations. Hence, the willingness to pay for the good in a given period $t$, which equals the equilibrium price $P_{t}$ charged by the monopolistic firm, can be stated as

$$
P_{t}=v-(1-\gamma)\left(1-\bar{x}_{t}\right) h
$$

Firms

We consider a firm of type $\theta, \theta=L, H, L<H$, which sells a good that may bring harm to the consumer. The probability of this event occurring in period $t$ is given by $1-x_{\theta t}$, where $x_{\theta t}$ represents the precaution the firm of type $\theta$ exerts in period $t$. A firm of type $\theta$ bears the costs of care $C\left(x_{\theta t}, \theta\right)=\theta \times x_{\theta t}^{2}$. Consequently, the type of firm determines the level of precaution costs and marginal precaution costs. However, in our analysis, firm type is private information. The ex ante probability that a firm is of type $L$ is equal to $\alpha, \alpha \in(0,1)$ and common knowledge. Neglecting production costs, a firm of type $\theta$ bears $\theta x_{i t}^{2}+\gamma\left(1-x_{\theta t}\right) h$ as expected costs. Thus, expected profits in period $t$ can be stated as

$$
\begin{aligned}
\pi_{\theta t} & =P_{t}-C\left(x_{\theta t}, \theta\right)-\gamma\left(1-x_{\theta t}\right) h \\
& =v-(1-\gamma)\left(1-\bar{x}_{t}\right) h-\theta x_{\theta t}^{2}-\gamma\left(1-x_{\theta t}\right) h
\end{aligned}
$$

\section{The analysis}

\subsection{Preliminaries}

The model we consider features asymmetric information regarding firm type or, to be more specific, with regard to precaution costs. Precaution costs dependent on type may cause different firm types to take different levels of care. Such differences in care levels are of interest to the buyer as there is incomplete compensation in the event of 
an accident. This implies that goods with different levels of precaution are differently valued by consumers and that consumers' willingness to pay depends on expected care. The way in which consumers' expectations regarding firm type depend on care observed in the first period is therefore of great relevance to firm profits.

Referring back to (2) and without further specifying expected care $\bar{x}_{2}$, we can state the expected profits of a firm of type $\theta$ in period 2 as

$$
\pi_{\theta 2}=v-(1-\gamma)\left(1-\bar{x}_{2}\right) h-\theta x_{\theta 2}^{2}-\gamma\left(1-x_{\theta 2}\right) h
$$

Two things are readily apparent. First, the expectations with respect to care, which are affected by the belief about the firm's type, have a clear level effect on profits in the second period. Second, incentives for care-taking in the second period are due only to payments in that period and will therefore be type-specific. Indeed, profit-maximizing firms ought to choose

$$
x_{\theta 2}^{*}=\frac{\gamma h}{2 \theta}
$$

which is dependent on type $\theta$, the level of harm $h$, and the share of losses firms have to bear $\gamma$. Care-taking in the second period is always non-strategic and thus type-revealing, where $x_{L 2}^{*}>x_{H 2}^{*}$.

If we were to assume that consumers have perfect information on the firm's type, profits in both periods would be given by

$$
\pi_{\theta t}=v-(1-\gamma)\left(1-\bar{x}_{\theta t}\right) h-\theta x_{\theta t}^{2}-\gamma\left(1-x_{\theta t}\right) h
$$

and the optimization with respect to care would yield (4) as the optimal choice by firm $\theta$ in periods 1 and 2 .

Lemma 1 If consumers are not informed about precaution but are informed about firm type, the profile of first-period and second-period care of a firm of type $\theta$ is $\left(\frac{\gamma h}{2 \theta}, \frac{\gamma h}{2 \theta}\right)$.

The case in which consumers know firm type is a benchmark. We consider it to be more realistic that firm type is private information. Such private information may distort precautionary behavior in period 1 . In the following, we inquire (i) whether distortions do indeed follow due to private information on firm type, and (ii) whether, if distortions occur, these are detrimental to welfare. It may be possible for asymmetric information on firm type to have a welfare-increasing effect. Due to the fact that firms bear less than full harm, i.e. $\gamma<1$, firms take less than socially optimal care as consumers bear the share $(1-\gamma)$ of harm which is not reflected in the firms' optimization problem (see, e.g., Shavell 2007). ${ }^{2}$ We assume that a decrease in the sum of expected harm and care costs is synonymous with an increase in welfare.

\footnotetext{
${ }^{2}$ In our analysis, we do not allow for punitive damages which might counter detrimental consequences following from $\gamma$ being less than one.
} 
We now refer back to (3) and turn our attention to expected care in the second period, i.e. to $\bar{x}_{2}$. Denoting with $q$ the probability that consumers assign to the possibility of the given firm having low costs, we obtain $\bar{x}_{2}=(1-q) x_{H 2}^{*}+q x_{L 2}^{*}$. Expected care in the first period is given by $\bar{x}_{1}=\alpha \hat{x}_{L 1}+(1-\alpha) \hat{x}_{H 1}$, where $\hat{x}_{\theta 1}$ denotes equilibrium care taken by a firm of type $\theta$ in period 1 . We have argued above that second-period care reveals firm type, yet this need not hold for first-period care. We now proceed to seek equilibria that are possible in the framework at hand.

\subsection{The signaling game}

Precaution taken in period 1 may signal type information. Consumers update their beliefs $q$ concerning firm type subsequent to observing first-period care. The equilibrium concept applied in the following is that of a perfect Bayesian equilibrium. However, there are a multiplicity of equilibria in signaling games. The leeway granted by the concept of the perfect Bayesian equilibrium in specifying the beliefs is often criticized and the intuitive criterion developed by Cho and Kreps (1987) is a widely accepted refinement applied in order to make beliefs more convincing (e.g. Rasmusen 2007). Consequently, we apply the intuitive criterion in our analysis as well. In the following, we will first elaborate on the perfect Bayesian equilibrium which is robust to the application of the intuitive criterion for every level of harm that must be compensated by the firm. For completeness, we afterwards briefly discuss various perfect Bayesian equilibria which are not robust to the application of the intuitive criterion. This criterion requires out-of-equilibrium beliefs to be intuitive in that, if a firm deviates from the equilibrium care level to another level which - for any beliefs - is dominated only for high-cost firms, the firm undertaking this deviation should be recognized as a low-cost firm. In our framework, with respect to beliefs it is ideal for firms if consumers expect low-cost firms with certainty when observing the deviation, as this expectation results in the maximal profit level for the firm in period 2.

Using the reasoning delineated in Sect. 3.1, we can state profits in the second period for a firm of type $\theta$, depending on whether or not consumers have used first-period care to update $q$ away from $\alpha$. If consumers believe that the firm is of the low-cost type, then we obtain

$$
\pi_{\theta 2}=v-(1-\gamma)\left(1-\frac{\gamma h}{2 L}\right) h-\theta\left(\frac{\gamma h}{2 \theta}\right)^{2}-\gamma\left(1-\frac{\gamma h}{2 \theta}\right) h
$$

as the level of second-period profits for a firm of type $\theta$, whereas it is

$$
\pi_{\theta 2}=v-(1-\gamma)\left(1-\frac{\gamma h}{2 H}\right) h-\theta\left(\frac{\gamma h}{2 \theta}\right)^{2}-\gamma\left(1-\frac{\gamma}{2 \theta}\right) h
$$

if consumers believe that the firm is of the high-cost type. In contrast, if consumers believe that both types could have produced the good which they purchased, i.e., if first-period care does not reveal information on the type of the firm, expected care in period two is given by 


$$
\bar{x}_{2}=(1-\alpha) x_{H 2}^{*}+\alpha x_{L 2}^{*}=\gamma h \frac{\alpha H+(1-\alpha) L}{2 L H}
$$

and second-period profits for a firm of type $\theta$ amount to

$$
\pi_{\theta 2}=v-(1-\gamma)\left(1-\gamma h \frac{\alpha H+(1-\alpha) L}{2 L H}\right) h-\theta\left(\frac{\gamma h}{2 \theta}\right)^{2}-\gamma\left(1-\frac{\gamma h}{2 \theta}\right) h
$$

The comparison of profit levels makes it evident that second-period profits of a lowcost firm are adversely affected if first-period care has not revealed its true type, whereas high-cost firms benefit from being pooled with low-cost firms. The benefit results from the fact that consumers use the weighted average of care by low-cost firms and high-cost firms in their calculation of expected care, where the weights correspond to the shares $\alpha$ and $(1-\alpha)$, respectively.

Without strategic considerations, profit-maximizing care in period 1 is equal to $\gamma h /(2 \theta)$. Given asymmetric information on firm type, it can be profit-maximizing to deviate from this level. This will depend on consumers' expectations regarding firm type, which are dependent on first-period care. For the firm, a trade-off may emerge between higher profits in period 2, due to an increase in consumers' willingness to pay, and lower profits in period 1, resulting from an altered care choice. The reason why firms may distort their choice of care depends on firm type. High-cost firms $(\theta=H)$ may seek to mix with the low-cost firms $(\theta=L)$ because consumers anticipate lowcost firms taking higher care in period 2. Low-cost firms profit from convincingly signaling their type in period 1 . This holds as any kind of pooling with the high-cost type negatively affects consumers' willingness to pay. Benefits from strategic behavior are dependent on the division of accident losses, i.e., the level of $\gamma$. The benefits that high-cost firms gain from mimicking are given by the difference between (9) and (7), which can be reduced to $\gamma(1-\gamma) \alpha h^{2} \frac{H-L}{2 H L}$. The increase in profits for low-costs firms as a result of separating is given by the difference between (6) and (9), which can be reduced to $\gamma(1-\gamma)(1-\alpha) h^{2} \frac{H-L}{2 H L}$. The respective benefits are increasing (decreasing) with $\gamma$ for $\gamma<(>) 1 / 2$ because there are two effects at work. Consumers are willing to pay more for the products of low-cost firms due to the lower accident probability in period 2. The difference in expected accident probabilities increases with $\gamma$. Counteracting this effect, consumers are less concerned about accidents if their share of expected harm is low, i.e., $\gamma$ is high. The downside of strategic care-taking for firms, i.e., the increase in first-period costs, is also a function of $\gamma$ and depends on the necessary deviation from non-strategic care levels, where necessity is critically dependent on consumers' expectations regarding firm type.

Despite having argued that there may be advantages in strategic care-taking, we will first consider whether there is an equilibrium entailing non-distorted care levels in the first period. Optimal care without strategic considerations for high-cost firms is $\frac{\gamma h}{2 H}$, whereas it is $\frac{\gamma h}{2 L}$ for low-cost firms. This difference may argue against high-cost firms mimicking low-cost firms in period 1 if $\gamma$ is sufficiently large. Consequently, we expect that there is an equilibrium without strategic distortions if $\gamma$ is large.

Proposition 1 Given $\gamma \geq 2 L /(H+L)$, there is a separating equilibrium in which low-cost firms choose $\left(x_{L 1}, x_{L 2}\right)=\left(\frac{\gamma h}{2 L}, \frac{\gamma h}{2 L}\right)$ and high-cost firms choose 
$\left(x_{H 1}, x_{H 2}\right)=\left(\frac{\gamma h}{2 H}, \frac{\gamma h}{2 H}\right)$ if consumers expect high-cost firms with probability $1-q=$ $1(0)$ when $x<(\geq) \frac{\gamma h}{2 L}$ in period one.

Proof It is obvious that low-cost firms choose $\frac{\gamma h}{2 L}$, given consumers' beliefs and highcost firms choosing $\frac{\gamma h}{2 H}$. However, it remains to be established that high-cost firms do not prefer to mimic low-cost firms, given consumers' beliefs and low-cost firms choosing $\frac{\gamma h}{2 L}$. To this end, we compare the sum of first-period and second-period profits of high-cost firms, both if they take $\frac{\gamma h}{2 H}$ and if they take $\frac{\gamma h}{2 L}$ :

$$
\begin{aligned}
v- & (1-\gamma)\left(1-\gamma h \frac{\alpha H+(1-\alpha) L}{2 L H}\right) h-H\left(\frac{\gamma h}{2 H}\right)^{2}-\gamma\left(1-\frac{\gamma h}{2 H}\right) h \\
& +v-(1-\gamma)\left(1-\frac{\gamma h}{2 H}\right) h-H\left(\frac{\gamma h}{2 H}\right)^{2}-\gamma\left(1-\frac{\gamma h}{2 H}\right) h \\
& -\left[v-(1-\gamma)\left(1-\gamma h \frac{\alpha H+(1-\alpha) L}{2 L H}\right) h-H\left(\frac{\gamma h}{2 L}\right)^{2}-\gamma\left(1-\frac{\gamma h}{2 L}\right) h\right] \\
& -\left[v-(1-\gamma)\left(1-\frac{\gamma h}{2 L}\right) h-H\left(\frac{\gamma h}{2 H}\right)^{2}-\gamma\left(1-\frac{\gamma h}{2 H}\right) h\right] \\
= & \frac{\gamma h^{2}(H-L)(\gamma(H+L)-2 L)}{4 H L^{2}}
\end{aligned}
$$

First-period expected care is $\bar{x}_{1}=\gamma h \frac{\alpha H+(1-\alpha) L}{2 L H}$ as we are testing whether there is an equilibrium in which low-cost (high-cost) firms choose $\gamma h /(2 L)(\gamma h /(2 H))$. The last simplified expression of the difference in profits reveals that it is not profitable for high-cost firms to mimic low-cost firms whenever the share of losses borne by the firm is sufficiently high, i.e., if $\gamma \geq 2 L /(H+L)$.

The above establishes the existence of a perfect Bayesian equilibrium of this kind. We will now argue that this equilibrium is robust to the application of the intuitive criterion. Both types of firms choose their non-strategic levels of precaution in the first period for $\gamma \geq \frac{2 L}{H+L}$ and consumers expect high-cost firms with probability $1-q=1(0)$ when $x<(\geq) \frac{\gamma h}{2 L}$. The beliefs which support this separating equilibrium are intuitive, in that for a high-cost firm, choosing greater care in order to disguise itself as a low-cost firm is a dominated strategy, while choosing a lower level of care decreases the profits of low-cost firms. In summary, this equilibrium remains even after applying the intuitive criterion.

Corollary 1 If the equilibrium described in Proposition 1 results, asymmetric information on firm type does not change social costs.

Proof This deduction clearly follows from the fact that care choices are the same with or without asymmetric information about firm type.

If the share of losses borne by the firm is large, we obtain a separating outcome in which care levels are the same as if consumers knew firm type. In practice, the share 
$\gamma$ will usually be high if the harm is done to an object which is, for instance, easy to value. Smaller values of $\gamma$ are more likely in cases where pain and suffering are part of the harm, as courts are hesitant to compensate such harm generously (see, e.g., Visscher 2009). We now consider the existence of a separating equilibrium where the share of losses $\gamma$ is small.

The discussion above suggested that for low values of $\gamma$, i.e., $\gamma<\frac{2 L}{H+L}$, high-cost firms would mimic low-cost firms, were consumers to expect low-cost firms whenever they observe $x=\frac{\gamma h}{2 L}$. As a result, the non-strategic care level is no longer sufficient for low-cost firms to signal their type if consumers are rational. That is why low-cost firms might choose to perform a level of care in period 1 higher than the non-strategic care level and dominated by the perspective of a high-cost firm to signal its type. When experiencing this higher level of care, consumers will recognize the firm as being of the low-cost type. We will now determine this critical level of care $x_{c}$ which makes it profitable for the high-cost firm to choose $\frac{\gamma h}{2 H}$ and thereby reveal its type, instead of mimicking the low-cost firm. In other words, we require a separating equilibrium in which the low-cost firm chooses $x_{c}$ and the high-cost firm chooses $\frac{\gamma h}{2 H}$. In this case, $\bar{x}_{1}=\alpha x_{c}+(1-\alpha) \frac{\gamma h}{2 H}$ holds. The care level that is high enough to make the high-cost firm indifferent about taking $x_{c}$ or $\frac{\gamma h}{2 H}$ follows from a comparison of profits for the respective care levels. Consumers' expectations for period $1, \bar{x}_{1}$, are as established above and consumers believe that the firm who supplied the good in period 1 is high-cost with probability $1-q=0(1)$ when $x \geq(<) x_{c}$.

$$
\begin{aligned}
v- & (1-\gamma)\left(1-\alpha x_{c}-(1-\alpha) \frac{\gamma h}{2 H}\right) h-H\left(\frac{\gamma h}{2 H}\right)^{2}-\gamma\left(1-\frac{\gamma h}{2 H}\right) h \\
& +v-(1-\gamma)\left(1-\frac{\gamma h}{2 H}\right) h-H\left(\frac{\gamma h}{2 H}\right)^{2}-\gamma\left(1-\frac{\gamma h}{2 H}\right) h \\
= & v-(1-\gamma)\left(1-\alpha x_{c}-(1-\alpha) \frac{\gamma h}{2 H}\right) h-H\left(x_{c}\right)^{2}-\gamma\left(1-x_{c}\right) h \\
& +v-(1-\gamma)\left(1-\frac{\gamma h}{2 L}\right) h-H\left(\frac{\gamma h}{2 H}\right)^{2}-\gamma\left(1-\frac{\gamma h}{2 H}\right) h
\end{aligned}
$$

Solving the equation for the critical level of care gives

$$
x_{c}=\frac{\gamma h L+\sqrt{2 \gamma(1-\gamma) h^{2} L(H-L)}}{2 H L}
$$

Proposition 2 Given $\gamma<2 L /(H+L)$, there is a separating equilibrium in which low-cost firms choose $\left(x_{L 1}, x_{L 2}\right)=\left(x_{c}, \frac{\gamma h}{2 L}\right)$ and high-cost firms choose $\left(x_{H 1}, x_{H 2}\right)=$ $\left(\frac{\gamma h}{2 H}, \frac{\gamma h}{2 H}\right)$ if consumers expect high-cost firms with probability $1-q=0$ (1) when $x \geq(<) x_{c}$ in period one.

Proof The optimality for the high-cost firm of sticking to $\frac{\gamma^{h}}{2 H}$ in the first and second period, provided the low-cost firm chooses $x_{c}$ and beliefs are as specified, has been established in the derivation of $x_{c}$. The optimality for low-cost firms of choosing $x_{c}$ 
instead of $\frac{\gamma h}{2 L}$ follows from the fact that the benefits from taking the strategic care level $x_{c}$ are the same for both types, while the increase in costs as a result of deviating from the non-strategic care level are lower for low-cost firms.

The above establishes the existence of a perfect Bayesian equilibrium of this kind. As a next step, we will reason that this equilibrium is robust to the application of the intuitive criterion and then highlight the welfare consequences. High-cost firms choose their non-strategic level of care in the first period, whereas low-cost firms signal their type by choosing $x_{c}>\frac{\gamma h}{2 L}$, where $x_{c}$ has been established by considering dominance from a high-cost firm's perspective. Accordingly, consumers' beliefs, with consumers expecting high-cost firms with probability $1-q=1(0)$ when $x<(\geq) x_{c}$, are perfectly in line with the refinement of the intuitive criterion.

Corollary 2 If the equilibrium described in Proposition 2 results, asymmetric information on firm type lowers social costs.

Proof This result follows from the fact that $x_{c}$ is higher than $\frac{\gamma h}{2 L}$ for $\gamma<2 L /(H+L)$ but always below first-best care for low-cost firms, which is given by $\frac{h}{2 L}=\arg \min _{x}\{(1-$ $\left.x) h+L x^{2}\right\}$. The latter holds because (i) $\lim _{\gamma \rightarrow 2 L /(H+L)} x_{c}=\frac{\gamma h}{2 L}=\frac{h}{H+L}<\frac{h}{2 L}$ and $x_{c}$ is monotonously increasing in $\gamma$ for the relevant interval, and (ii) social costs are decreasing monotonously in care $x_{L 1}=x_{c}$ as long as $x_{c}<\frac{h}{2 L}$.

The above establishes that there is a separating equilibrium for every level of $\gamma$, as the interval for $\gamma$ used in Proposition $1, \gamma \in\left[\frac{2 L}{H+L}, 1\right)$, complements the respective interval for $\gamma$ used in Proposition 2, $\gamma \in\left(0, \frac{2 L}{H+L}\right)$. In Fig. 1, we use the specification of $\alpha=0.5, h=1=L<2=H$, and illustrate first-best care levels given by $1 / 2=\arg \min _{x}\left\{1-x+x^{2}\right\}$ and $1 / 4=\arg \min _{x}\left\{1-x+2 x^{2}\right\}$ as well as $\gamma /(2 L)=\gamma / 2$, $\gamma /(2 H)=\gamma / 4$ and $x_{c}$ for $\gamma<\frac{2 L}{H+L}=\frac{2}{3}$ to give an idea of the different separating equilibria that are possible and the degree to which care taken deviates from first-best care. Given that social costs, consisting of care costs and expected harm, are a convex lunction with respect to care taken by firms, an increase in care always reduces social costs, as long as care does not exceed its first-best level. In this case, costs of higher care-taking are always more than compensated by the reduction in expected harm. ${ }^{3}$

The separating equilibrium established above is unique for a given share of losses borne by the firm and consistent with the application of the intuitive criterion. In the following, for completeness' sake and in order to establish the uniqueness of the above equilibrium, we briefly lay out other perfect Bayesian equilibria and provide intuition for why they are not robust to the application of the intuitive criterion. We will start our inquiry with the possibility that low-cost firms go to more extreme levels of precaution in order to credibly signal type.

Low-cost firms may increase their level of care in the first period in order to separate from high-cost firms. The level of care we have considered for that purpose, $x_{c}$, is the

3 A sufficient condition for this to hold is that the firms' cost function and expected harm are weakly convex functions with respect to care-taking, with strict convexity for one of the two functions. This ensures a unique level of first-best care and less than first-best (non-strategic) care levels taken by firms in a setting in which strict liability and incomplete victim compensation apply. 


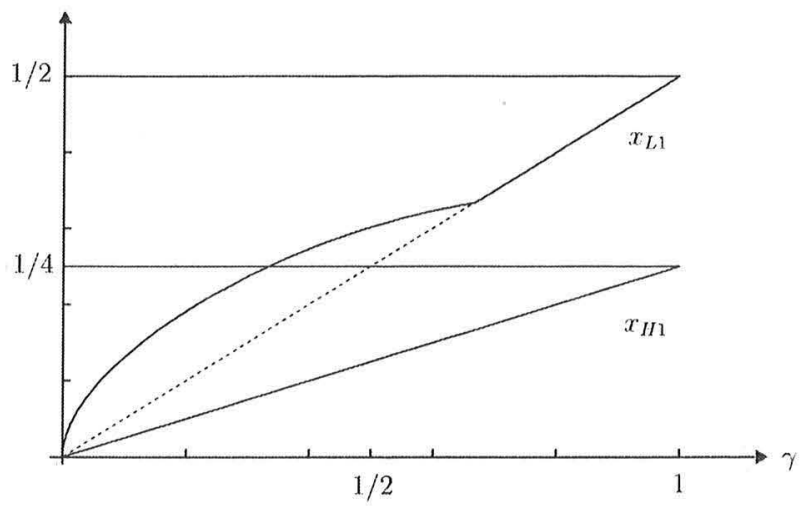

Fig. 1 Care levels $x_{L 1}, x_{H 1}, 1 / 4$, and $1 / 2$ as a function of $\gamma$

minimum level for low values of $\gamma$, while low-cost firms choose non-strategic care for high values of $\gamma$. However, low-cost firms may be willing to take even greater care if consumer beliefs call for it and the concept of the perfect Bayesian equilibrium gives much leeway regarding consumers' expectations. So, it is possible to establish the maximum level of care that the low-cost firm would choose in order to discourage high-cost firms from mimicking them, provided that consumers' beliefs require such a high level in order to expect low-cost firms with certainty. This maximal level $\tilde{x}$ causes the low-cost firm to be indifferent with regard to choosing $\tilde{x}$ or $\frac{\gamma h}{2 L}$, given high-cost firms take $\left(\frac{\gamma h}{2 H}, \frac{\gamma h}{2 H}\right)$ and consumers expect a high-cost firm with probability $1(0)$ if $x<(\geq) \tilde{x}$. The level $\tilde{x}$ thus follows from a comparison of a low-cost firm's profits taking $\tilde{x}$ or non-strategic care, and consumers expect $\bar{x}_{1}=\alpha \tilde{x}+(1-\alpha) \frac{\gamma h}{2 H}$. This critical care level is so large that it exceeds the first-best care level for sufficiently high $\gamma{ }^{4}$ However, note that the beliefs used to support this equilibrium are not intuitive. Consumers should expect a low-cost firm with certainty, even if they were to observe a precaution level somewhat lower than $\tilde{x}$, because this choice is dominated only for high-cost firms, even for the most favorable beliefs by consumers. In summary, separating equilibria in which low-cost firms choose a higher level of first-period care than $x_{c}\left(\frac{\gamma h}{2 L}\right)$ for $\gamma<\frac{2 L}{H+L}\left(\gamma \geq \frac{2 L}{H+L}\right)$ are ruled out by the application of the intuitive criterion.

After having discussed possible separating equilibria, we now scrutinize the existence of pooling equilibria. We note from the start that no pooling equilibrium will be robust to the application of the intuitive criterion. We first consider the possibility that both the low-cost and the high-cost firm choose the low-cost firm's non-strategic level of care, $\frac{\gamma h}{2 L}$, in the first period. For such an outcome to be an equilibrium, beliefs need to be consistent with actual behavior. Therefore, consumers should expect high-cost firms with probability $1-q=1(1-\alpha)$ when $x<(\geq) \frac{\gamma h}{2 L}$. Through a comparison of profits for high-cost firms when choosing their own non-strategic care level or that associated with low-cost firms, such an equilibrium can be established for $\gamma \leq \frac{2 \alpha L}{H-L+2 \alpha L}$. Given

4 Proofs for this and the equilibria discussed below are available from the authors upon request. 
consumers' beliefs, low-cost firms will not deviate to higher care levels, as this is not rewarded by consumers because credible signaling is not possible. Consequently, both firm types choosing the low-cost firm's non-strategic care constitutes a perfect Bayesian equilibrium given the restriction on $\gamma$. In this equilibrium, first-period care-taking by high-cost firms exceeds the high-cost firm's non-strategic care level but is lower than the high-cost firm's first-best care level, implying a reduction in social costs due to asymmetric information on firm type. However, this equilibrium is not robust to the application of the intuitive criterion. There is a critical level of precaution which makes the high-cost firm indifferent as regards choosing this level of care over the low-cost firm's non-strategic care level, even if the deviation towards the critical value implies that consumers believe the firm to be of the low-cost type with certainty. This follows from the fact that benefits from higher care are the same for both firm types, namely the consumers' increased willingness to pay in the second period, while the increase in costs due to the higher care level is larger for the high-cost firm than for the low-cost firm. In summary, this pooling equilibrium does not withstand the application of the intuitive criterion.

The pooling equilibrium just discussed and ruled out by the intuitive criterion is a natural one, as it implies that both firm types choose the low-cost firm's non-strategic care. However, a pooling equilibrium may also be established for higher levels of care than the non-strategic care level for low-cost firms, and allow for a saving in social costs compared to a situation with symmetric information about firm type. Yet, we do not dwell on this issue here, as this type of equilibrium is also not supported by the intuitive criterion. Again, there always exists some higher precaution level that should allow low-cost firms to credibly signal their type, following the reasoning laid out above.

All in all the above discussion allows us to arrive at our central result.

Proposition 3 For every given value of $\gamma$ there exists a unique perfect Bayesian equilibrium, robust to the application of the intuitive criterion. For $\gamma<\frac{2 L}{H+L}$, lowcost firms choose $\left(x_{L 1}, x_{L 2}\right)=\left(x_{c}, \frac{\gamma h}{2 L}\right)$ and high-cost firms choose $\left(x_{H 1}, x_{H 2}\right)=$ $\left(\frac{\gamma h}{2 H}, \frac{\gamma h}{2 H}\right)$, given that consumers expect high-cost firms with probability $1-q=1(0)$ when $x<(\geq) x_{c}$. For $\gamma \geq \frac{2 L}{H+L}$, low-cost firms choose $\left(x_{L 1}, x_{L 2}\right)=\left(\frac{\gamma h}{2 L}, \frac{\gamma h}{2 L}\right)$ and high-cost firms choose $\left(x_{H 1}, x_{H 2}\right)=\left(\frac{\gamma h}{2 H}, \frac{\gamma h}{2 H}\right)$, given that consumers expect high-cost firms with probability $1-q=1(0)$ when $x<(\geq) \frac{\gamma h}{2 L}$.

Proof Follows from the discussion above.

Allowing only for equilibria which are consistent with the intuitive criterion, we conclude that our findings have the following welfare implications.

Corollary 3 Asymmetric information on firm type decreases (does not affect) social costs if $\gamma<(\geq) \frac{2 L}{H+L}$.

Proof The statement follows from Corollary 1 and 2.

Asymmetric information in the framework of this study can be beneficial given that there is already an imperfection present, namely the unobservability of care. 
Consequently, we find that asymmetric information on firm type (weakly) improves the outcome in a second-best sense (cf. Lipsey and Lancaster 1956).

\section{Conclusion}

Asymmetric information often changes behavior and thereby causes inefficiencies. In the setting presented, asymmetric information may also change behavior but does so in a (weakly) welfare-improving way. Due to imperfect information on care taken and less than full compensation under strict liability, firms take too little care when firm type is public information. Given asymmetric information on both care taken and firm type, firms take weakly greater care. Applying the concept of a perfect Bayesian equilibrium together with the refinement of the intuitive criterion, we establish a unique scparating equilibrium. It holds that the level of care for low-cost firms is higher (unchanged) for the case in which the firm bears a low (high) share of the harm, but never exceeds the first-best level. Without refining the concept of a perfect Bayesian equilibrium, we find that the equilibrium care level may even surpass first-best care. Still, the higher care taken is often welfare-improving compared to the alternative level of care which results if consumers know the firm type.

Our analysis suggests the following policy implications. It often holds true that regulation occurs with the first-best in mind. Relating to this benchmark, policy makers sometimes attempt to combat imperfections by following a piecemeal approach. However, it may be the case that some imperfections cannot be overcome. If this is so, addressing other imperfections may be detrimental to welfare. In our case, we take imperfect compensation of victims and imperfect information on care as given. Our analysis shows that the additional imperfection of asymmetric information on firm type can actually further welfare.

Acknowledgments We are indebted to Eberhard Feess, Laszlo Goerke, and two anonymous referees for very helpful suggestions.

\section{References}

Bagwell K, Riordan MH (1991) High and declining prices signal product quality. Am Econ Rev 81:224-239 Cho IK, Kreps DM (1987) Signaling games and stable equilibria. Q J Econ 102:179-221

Cooter R, Ulen T (2008) Law and economics, 5th edn. Addison Wesley, Boston

Daughety A, Reinganum J (1995) Product safety: liability, R \& D, and signaling. Am Econ Rev 85:11871206

Daughety A, Reinganum J (2008) Products liability, signaling and disclosure. J Inst Theor Econ 164:106126

Endres A, Lüdecke A (1998) Incomplete strict liability: effects on product differentiation and information provision. Int Rev Law Econ 18:511-528

Geistfeld MA (2009) Products liability. In: Faure M (ed) The encyclopedia of law and economics, 2nd edn. Edward Elgar, Cheltenham

Lipsey RE, Lancaster K (1956) The general theory of second best. Rev Econ Stud 24:11-32

Marette S, Bureau J-C, Gozlan E (2000) Product safety provision and consumers' information. Aust Econ Pap 39:426-441

Polinsky AM, Shavell S (2009) The uneasy case for product liability. Harvard John M. Olin Discussion Paper Series No. 647 
Rasmusen E (2007) Games and information. Blackwell Publishing, Oxford

Shavell S (2004) Foundations of economic analysis of law. Harvard University Press, Cambridge

Shavell S (2007) Liability for accidents. In: Polinsky AM, Shavell S (eds) Handbook of law and economics, vol 1. Elsevier, Amsterdam, pp 139-182

Visscher L (2009) Tort damages. In: Faure M (ed) The encyclopedia of law and economics, 2nd edn. Edward Elgar, Cheltenham

Wickelgren A (2006) The inefficiency of contractually-based liability with rational consumers. J Law Econ Organ 22:168-183 